\title{
A CONTACT THEORY ANALYSIS OF SOUTH AFRICANS' PERCEPTIONS OF NIGERIAN IMMIGRATION
}

\author{
Efe Mary Isike \\ Department of Anthropology and Development Studies \\ University of Zululand \\ isikee@unizulu.ac.za
}

\begin{abstract}
Xenophobia targeted at African immigrants is a recurring problem that has made post-apartheid South Africa notorious around the world. The dramatic and violent nature of this xenophobia which peaked in May 2008 and April and October 2015 has raised questions about intergroup relations between South Africans and African migrants. Although the two spates of attacks assumed a similar pattern, the consequences differed. In 2015, the government took a firmer stand against xenophobia and African countries stood up against the attacks on their citizens. This begs the question of whether contact between the two groups has enabled concord or discord. Scholars have divergent views on the effect of contact between diverse groups. This article explores South Africans' perceptions of African immigration through the lens of contact theory. A qualitative research methodology was adopted and primary data was generated from interviews with 32 South African respondents. These respondents were purposefully sampled from the social networks of 36 Nigerian migrants resident in Empangeni, KwaZulu-Natal. The findings show that contact between Nigerian migrants and South Africans had a paradoxical effect on the nature of the ties that evolved. In most cases, it fostered concord, while in others it resulted in hostility and prejudice.
\end{abstract}

Keywords: Contact theory, entanglement, conviviality, exclusion and African immigration.

\section{Introduction}

There is a plethora of studies on the nature of the relationship and interaction between immigrants and members of host communities. Immigration is a topical issue in demography because of its impact in changing the socio-cultural dimensions of the host community. These dimensions include the ethnic, economic, religious and other aspects of this community (Hugo 2005). A major challenge faced by members of the host community is not simply their socio-cultural evolution but how to address the cultural divide or diversity of the immigrants. Hugo (2005) notes, that, the increase in migration has heightened concerns about the extent to which host members accept growing socio-cultural differences in their communities. Host members have responded to social diversities in various ways, ranging from extreme exclusion to integration and tolerance. Bennet's (201 I: 29) study describes extreme poles of response as "the ideal of complete non-interaction: we don't engage, and we (and they) don't change. At the other pole is the ideal of complete amalgamation, from which some global homogenization eventually emerges." The main objective of this article is to explore how sustained contact has influenced the nature of relationships between South Africans and Nigerian migrants. It seeks to answer the question; has contact between Nigerian migrants and South Africans fostered concord or fuelled discord?

Contact theory is employed to analyse South Africans' perceptions of African migration. The social networks method was used to interview 32 South Africans residing in Empangeni who were identified by their Nigerian ties. These ties include relationships with friends, work colleagues and kin by marriage in a dyadic network relationship (South Africans and Nigerians). The framing of this discussion within contact theory is followed by the presentation and discussion of the findings.

\section{Literature Review and Theoretical Framework} Before delving into the paradoxical effects of contact, it is imperative to conceptualize the polarized responses of host communities to migration. As noted earlier, exclusion is a response of total nonacceptance of immigrants by members of host communities. It is an attempt by host members to create a 'pure' society without unwanted immigrants that would threaten and tarnish the social fabric of 
the host community as a result of their cultural differences. In other words, exclusion as a response can be the result of host members' perception of belonging to a relatively homogeneous group which regards other diverse groups as a potential threat to their social fabric. Social identity theory expounds on the process of exclusion based on group diversity. Studies of intergroup relations have employed this theory to emphasize differences and differentiation. Social identity theory posits that individual identities are a sub-creation of social identities that emanate from belonging to a group (Padilla and Perez 2003). Indeed, Hogg (1993) states that, to a large extent, belonging to a social group impacts on one's sense of self, that is, how one perceives oneself. Simply put, an individual derives his or her personal identity from the identity of the group he or she belongs to.

Furthermore, Stets and Burke (2000:226) argue that "having a particular social identity means being at one with a certain group, being like others in the group, and seeing things from the group's perspective... the basis of social identity is in the uniformity of perception and action among group members." Therefore, maintaining homogeneity is the main goal, discouraging the existence of differences among members. The paradox is that social groupings lead to the inclusion of those with a homogeneous identity and the exclusion of those perceived to be different, thereby perpetuating the us and them divide. Rubin and Hewstone (1998: 322) observe that "the mere perception of belonging to two distinct groups - that is, social categorization per se - is sufficient to trigger inter-group discrimination favouring the in-group." Social groupings encompass various levels. Isike (2015: 15) notes that these range "from the local scale of class identification within a social organisation; to ethnicity and race within territorial boundaries; a broader scale which encompasses national identity; and regional identity beyond territorial borders." At national level it is easier to police and exclude non-citizens as a result of mapped out territorial boundaries which are internationally recognised while at lower levels, certain groups are excluded by members of host communities through a softer form of exclusion known as differential exclusion. Strategies such as indigeneity, ethnicity, autochthony and ancestral linkages are entrenched in legislation and policies in order to exclude certain groups.

Differential exclusion does not totally exclude the unwanted migrants but strategically marginalizes them from accessing certain benefits in the host community. In most cases it is a response by members of the host community and in others it is initiated by the government. Differential exclusion initiated by government "is characterised by restrictive policies excluding immigrants from the political community, aimed at artificially maintaining a temporal character to immigration" (Regout 201 I:8). In this case migrants are permitted to function in limited spaces. Certain spaces are strictly regulated to ensure that migrants remain temporary and not permanent residents (Balzacq and Carrera 2006). These restrictions prevent migrants from being full incorporated into the host community. In some instances, they are temporarily admitted into the economic space of the host community but hindered from integrating politically or socio-culturally (Pentikainen 2008). "This is a win-win situation for the host country as in most cases it benefits economically from migrants' presence while ensuring their exclusion and retaining its social character" (Isike 2015: 16). The process entails "accepting immigrants only within strict functional and temporal limits: they are welcome as workers, but not as settlers; as individuals but not as families or communities; as temporary sojourners but not as long-term residents" (Schierup et al 2006: II). Countries that implement differential exclusion policies do not want to inhibit immigration but hesitate to accept migrants' presence (Vermeulen 1997).

The opposite response is one of entanglement and conviviality. These twin concepts focus on positive intergroup relations irrespective of differences. Entanglement discourse emphasizes the intersections of relationships and the inclusion of various groups irrespective of similarities and differences. It posits that although intergroup relations are characterised by hostility due to perceived differences, these groups create spaces for interaction. "It asserts that although categorization such as us and them exists, there is a point where these diversities meet and interact; not as assimilation or hybridity but at a juncture of interdependence" (Isike 20I5: 35). This interdependent relationship is described as the entanglement of differences. Entanglement is therefore a condition of being twisted together or entwined, involved with; it speaks of an intimacy gained, even if it was resisted, or ignored or uninvited... [A] Relationship or set of social relationships that is complicated, ensnaring, in a tangle, but which also implies a human foldedness. It works with difference and sameness but also with their limits, their predicaments, and their moments of complication (Nuttall 2009: I).

Nuttall explored race relations between Africans and Whites in post-apartheid South Africa. She explains that the need to create a relationship between these groups which was characterised by differentiation was the result of fear of the development of an interdependent relationship 
(Nuttall 2009). Amin (20/2) notes that, in Europe, fear is employed to create an imagined community founded on an ideal notion of uniformity, thereby excluding those migrants labelled as strangers due to their differences. According to the entanglement school of thought, focusing on differences in the study of intergroup relations is over-simplistic and myopic as it may not provide a holistic picture of the nature of their relations. According to Isike (2015: 35-36),

Scholars should therefore seek an intersecting space, a site where these differences overlap in order to understand the nature of such complex relationships... Although differences exist, they are not always clearly socially defined in the real world; categorizing them is problematic as there are grey areas where similarities and differences mingle.

These grey areas intersect between the we and them divide, from which emanates an us.

As noted earlier, entanglement is closely related to the notion of conviviality that argues that, although differences exist in intergroup relations, they are incomplete and ever-changing; and if tolerated they make a complete whole. This involves renegotiation of differences in order to produce a bridge between the us and them divide. Nyamnjoh (20|5:II-I2) states that conviviality "stresses the pursuit of sameness and commonalities by bridging divides and facilitating interconnections... and an attitude towards identities and identification as open-ended pursuits." Therefore, conviviality as a disposition does not aim to attain homogeneity but a sense of belonging across heterogeneous relationships. Gilroy (2004:xi) notes that "the radical openness that brings conviviality alive makes nonsense of closed, fixed and reified identity and turns attention toward the always-unpredictable mechanisms of identification." For him, in a multicultural world,

It is important to ask what critical perspectives might nurture the ability and the desire to live with difference on an increasingly divided but also convergent planet? We need to know what sorts of insight and reflection might actually help increasingly differentiated societies and anxious individuals to cope successfully with the challenges involved in dwelling comfortably in proximity to the unfamiliar without becoming fearful and hostile (Gilroy 2004:3).

Intergroup interaction is inevitable especially in cases where close proximity of differences threatens boundaries. Nuttall (2009) explains that boundaries of diversity are usually overcome within close proximity. Consequently, close proximity is a major factor that can create a convivial culture among diverse groups. A convivial culture is a "social pattern in which different metropolitan groups dwell in close proximity, but where their racial, linguistic and http://aps.journals.ac.za religious particularities do not... add up to discontinuities of experience or insuperable problems of communication" (Gilroy 2006:4). That is, people are very different but are also very similar and these divergent traits intersect to produce concord. Paradoxically, the multiple identities that make them so different also make them similar because these identities allow them to interact, thereby creating an interdependent relationship. Entanglement and conviviality create spaces that enable "different groups and individuals to focus on commonalities that intercut the dimensions of fixed difference which may cause fear and anxiety about the other" (Rzepnikowska 2013:4). Various geographic spaces propagate the formation of a convivial culture towards diversity. These are "sites for coming to terms with ethnic difference" (Amin 2012:79). Such spaces ultimately blur the lines of diversity as a result of frequent interaction between host members and migrants. Amin (2002:959) describes these sites as "micro-publics of everyday social contact and encounter". Interaction within these micro-publics is inevitable. Examples include religious settings, the academic environment, social clubs and workplaces that are breeding grounds for convivial relations among diverse groups (Carter and Jones 1989). Flowing from this, in intergroup relations, how does contact foster two paradoxical responses ranging from discord/exclusion to conviviality/concord?

Contact theory has been used by various scholars to explain diverse group behaviour (see Pettigrew 1998; Dixon and Durrheim 2003; and Dixon et al 2005). The theory posits that sustained interaction between diverse groups ultimately reduces prejudice (Dixon et al 2005:697). This will eventually lead to the dissipation of the cultural boundaries that separate groups into us and them, thereby creating a sense of inclusion. Consequently, in intergroup relations, sustained contact can reduce hostility and foster conviviality and therefore enable the integration of the out-group.

Nevertheless, studies have shown that contact has a paradoxical effect on intergroup relations. For instance, Dixon and Durrheim's (2003) study shows that contact between the in-group and out-group often engendered the reestablishment of cultural boundaries. They argue that while this does not debunk the theory; it oversimplifies the dynamics of diverse group relations (Dixon and Durrheim 2003). It is not a given that contact between diverse groups will produce tolerance and conviviality. In fact, contact has a dual effect of conviviality and exclusion on intergroup relations. Durrheim et al (2014) identify three major paradoxical effects of intergroup contact, namely, recategorization, anxiety reduction and the promotion of empathy. Pettigrew (1998: 75) 
states that "recategorization adopts an inclusive strategy that highlights similarities among the interactants and obscures the 'we' and 'they' boundary." This means that within the micro-public space, differentiation is overcome and differences are bridged. However, contact reduces the attitude of the out-group towards prejudice in the broader spectrum. These out-groups are recategorised, that is, removed from their mother group, as they do not resonate or identify with the experience of exclusion of the main group. This was captured in Dixon et al's (20I3) study on race relations between Whites and Blacks in South Africa. It found that although intergroup contact fostered concord between the two races, amongst Black people, contact "diminished their political perceptions of own group relative deprivation and discrimination and decreased support for policies designed to redress the legacy of apartheid" (Dixon et al 2013:243). Therefore, it could be inferred that, within smaller enclaves, contact reduces hostility but this does not translate to conviviality in broader spaces. Another paradoxical effect of contact is the development of antipathy rather than empathy. Dovidio et al (20/3) explain that a major tenet of contact discourse is that contact promotes empathic qualities which include compassion and care for the excluded group and this ultimately leads to self-other merging. Self-other merging is a process "where the in-group looks beyond their diversities and sees the out-group as similar to itself" (Isike 2015: 39). However, studies have shown that rather than producing self-other merging, contact has perpetuated antipathy towards the out-group and has been a catalyst for exclusion and hostility. Nalder (2002) states that contact may bolster the hierarchy, that is, unequal status, between the in-group and the out-group, rather than bridge the divide. Finally, contact theory argues that intergroup contact reduces anxiety and produces convivial relations (Pettigrew 2008). However, studies have shown that rather than reducing anxiety, it has fuelled hostility and exclusion. For instance, Enos (2014: 3700) states that "the mere presence of the out-group causes negative reactions, possibly because proximity increases the salience of the outgroup, thereby activating negative stereotypes."

In addressing these limitations of contact theory, scholars have argued that certain conditions need to be present for contact to foster conviviality and reduce prejudice. In the first instance, Dixon and Durrheim (2003: I) propose that contact has to be "intimate, cooperative and oriented towards the achievement of a shared goal. Moreover, it should occur between people of equal status." Intimate intergroup contact denotes that the nature of interaction between the in-group and out-group is informal and personal, so that they can learn to understand each other. This is of paramount importance because prejudice is "often as a result of false beliefs, misconceptions and stereotypes" (McBride 2015: 15). Thus, intimacy of contact will cause the in-group to rethink preconceived notions as common new identities are discovered through personal contact and the process of self-other merging occurs. Brewer and Miller (1984: 288-289) suggest that intimacy of contact is "more likely to generalize to new structures because extended and frequent utilization of alternative information featured in interactions undermines the availability and usefulness of category identity as a basis for future interactions with the same or different individuals." The second condition is to ensure that contact between the two groups is cooperative towards a common goal. Dixon and Durrheim (2003) state, that, there is a tendency for convivial culture to emanate in cases where diverse groups co-operate and work together as a team. This is because the common motivation that drives them supersedes their differences and produces a convivial culture. Conversely, intergroup relations that are competitive lead to exclusion, as members perceive themselves as rivals. Everett and Onu (2013) argue that group members must work together in a non-competitive environment in order to produce conviviality. Finally, equal status is important in intergroup relations as the absence of this condition implies hierarchy and subordination. Pettigrew and Tropp (2006) note that in order for conviviality to develop, intergroup contact must be founded on equality, that is, there is no discrimination and these groups perceive themselves as equals. As noted earlier, these conditions have to be present for prejudice to evaporate and convivial relations to develop. Studies such as that by Hamberger and Hewstone (1997) have validated these arguments.

\section{Data Source and Methods}

Primary data was generated from interviews conducted with 32 South Africans. These respondents were purposefully sampled from the social networks of 36 Nigerian migrants resident in Empangeni, KwaZulu-Natal. The Nigerian migrants were also interviewed but this article focuses only on the South Africans' responses. The Nigerian migrants were sampled using stratified random sampling. The migrant population was divided into sub-groups in order to ensure that all the elements of the population were represented in the sample (Bless and Higson-Smith 1995). The sample was drawn from a voluntary association known as the Association of Nigerian Residents in Umhlathuze (ANRU) in Empangeni. It has more than 60 registered 
members who are Nigerian migrants residing in the area. It is estimated that the membership of the ANRU makes up about $50 \%$ of Nigerian migrants known to be residing in the Umhlathuze area (Isike 2015). However, it is difficult to estimate the total stock of Nigerian migrants in Empangeni due to the presence of illegal migrants. The lottery sampling method (see Rivera and Rivera 2007) was used to select the sample of 36 Nigerian migrants that were requested to identify their most important South African dyadic tie since they immigrated to the country. Only 32 identified the South Africans who formed the sample for the study, made up of II females and 21 males. This selection approach is a combined procedure "used to identify a population of interest and construct the social network from informants" (Rothenberg 1995: 106). Nigerian migrants were specifically sampled for the main study because of the general stereotypes and prejudices South Africans have towards Nigerians as criminals, disease carriers and drug pushers. Crush and Ramachandran (20I4) acknowledge that amongst the migrant groups in South Africa, Nigerian migrants are one of the most disliked. Based on this argument, the study sought to investigate the South Africans' perceptions of Nigerian migration in Empangeni. Empangeni was selected as the study area for its unique character that makes it an attractive destination for Nigerian migrants. It hosts both transnational and national migrants who are employed in the various rural towns that surround it, including Felixton, Kwadlangezwa, Ngwelezane, Esikhawini, Eshowe, and Machane among others. Migrants reside in Empangeni and travel to and from their various places of work on a daily basis. The Richards Bay port, the university in Kwadlangezwa, and the hospital in Ngwelezane also make Empangeni an attractive spot for labour migrants seeking employment. Another rationale for selecting this area is that most studies on African migrants' relations with South Africans have been carried out in large metropolitan areas (Isike 2015). Focusing on experiences in a smaller town provides a holistic view of intergroup relations in South Africa.

A single instrument in the form of qualitative interviews was used to collect primary data. Compared to the quantitative type, qualitative interviews are unstructured, allowing for flexibility in order to capture the in-depth experiences of the respondents. Content analysis, which is a qualitative technique, was employed to analyse the secondary and primary data. Neuendorf (2002: 10) defines content analysis as "a summarizing, quantitative analysis of messages that relies on the scientific method (including attention to objectivity, intersubjectivity, a priori design, reliability, validity, generalisability, replicability, and hypothesis testing) and is not limited as to the types of variables that may be measured or the context in which the messages are created or presented." Babbie and Mouton (2006) describe it as a method of data analysis that can be used on any kind of communication in social science research.

\section{Findings and Discussion}

The findings presented in this section are based on the interviews conducted with the 32 South African respondents. Pseudonyms are used to ensure anonymity. The respondents that were identified by the migrant respondents were questioned on the nature of their relationship with the Nigerian migrants. They described the various types of relationships including friendship ties, ties with spouses/partners, work colleagues and clergymen. Seven female respondents cited spouses, while II male and two female respondents mentioned friends. Five male respondents and one female respondent identified work colleagues and clergy, respectively.

The respondents were asked about their general perceptions of African immigration to South Africa. The majority was not opposed to African migration; however, they felt that the government should formulate strict policies to regulate and decrease the influx of African migration to South Africa. Eighteen (56\%) respondents that supported strict immigration regulations provided various reasons, including reducing competition for goods and services between African migrants and host members and selective exclusion of certain migrants. This group was made up of II males and seven females. For example, according to Thembi:

I am not opposed to people coming to South Africa from Africa. My only problem is how people enter into this country without being properly scrutinized... South Africa can benefit from Africa(n) migration if only we allow those that can benefit us. Africa(n) migration must be regulated in a way that profits the country (Interviewed II/I0/I4).

This viewpoint, which states that African migrants should be filtered to ensure that only those that suit the social and economic fabric and needs of South African society are allowed entry, exemplifies selective tolerance. This is in line with the argument that cosmopolitanism is dependent on economic position (Yeoh 2013). Economic diversity and not cultural difference is a major yardstick for selective exclusion and inclusion of migrants in this context. Yeoh (2013:97) argues that "those identified as 'foreign talent' are welcomed and valorised as migrant talent which energises society..., those who are not - i.e. foreign workers - tend to be treated as disposable labour." It is evident that host members 
that favour strict prohibition seek to employ economic diversity as a tool for selective exclusion (Isike 20|5).

Furthermore, five (16\%) of the respondents, consisting of four males and one female, proposed that government totally ban African migration to South Africa. Their reasons included preventing the import of diseases from other African countries, curbing criminal activities, preserving the homogeneity of the country by protecting the local culture and ensuring that jobs are reserved for South Africans. These respondents seek to maintain the socio-cultural and economic fabric of South Africa not by tolerating differences but by totally excluding African migrants. They not only favour exclusion at the borders, but assimilation of those already in the country to fit the socio-cultural fabric of society. This concurs with Regout's (20II) position that exclusion entails the implementation of restrictive immigration legislation that ensures that immigrants do not integrate and the creation of a society that is free from unwanted immigrants who would threaten the socio-cultural life of host communities. While the latter may be the case with these respondents, they seem to only advocate for restrictive immigration policies that will exclude African migrants at the borders and not necessarily policies to prevent their integration. For instance, Paul, talks about acceptance of those already in the country as long as they respect the South African lifestyle. Thus, migrants that are already within the geographical space must assimilate into the culture of the host community. These views are in contrast to the friendships these South Africans have with Nigerian migrants within their network and also demonstrate their xenophobic tendencies. For example, the same Paul who advocates for the exclusion of African migrants at the borders speaks of a convivial relationship with his Nigerian dyad, Mark who he wants to learn isiZulu (assimilation):

Mark is a very good friend of mine. He is my chommie [Afrikaans word for friend]... That guy got my back (Interviewed 09/08/I4).

Paul's views on African immigration to South Africa show that the contact theory does not always work well in practice. As noted earlier, the theory argues that sustained intergroup interaction and contact will ultimately result in less prejudice and exclusion (Dixon et al 2005). Based on this premise, it could be assumed that Paul's friendship with his Nigerian dyad, Mark, would have removed his prejudice to African migration. However, this was not the case. This does not imply that the contact theory is invalid, but that it is not a given in all cases. On the other hand, in Ntuli's experience, contact enabled the development of conviviality and removal of prejudice. Due to his sustained interaction and contact with Shola, his Nigerian dyad, Ntuli's stereotypical views about Nigerian migrants changed. This is captured in his response to the question on whether cultural differences influenced his relationship with Shola:

Maybe initially, but as we became friends, that disappeared as I came to know more about Nigerians. Shola is truly Nigerian... We used to argue a lot about my past misconceptions of Nigerians... They are not bad people. I used to think they were all criminals... From close contact, I can see we are almost the same... He changed my mind-set not just about Nigerians but about Africans and our common humanity (Interviewed I / / I/I4).

Based on the aforementioned cases, it is evident that sustained intergroup interaction could produce two opposite outcomes; one blurring the lines of difference as was the case with Ntuli and the other having no influence on these demarcations as was the case with Paul. According to Ntuli:

Cultural differences actually made me understand the culture of Nigerians. I have learnt some Nigerian words, I eat the food and I wear the clothes... If I didn't meet Shola I don't think I would be this open to Nigerians. I am even planning to go there next year (Interviewed I2/1 1//4).

Ntuli's experience also shows that intimacy of contact was a major factor that influenced the development of a convivial culture in his relations with Nigerians.

Finally, one group of respondents stated that African migration should be permitted without any restrictions. These nine (28\%) respondents which included six males and three females argued that this would enable the formation of interdependent relations and cooperation among African countries, which in the long run, will invariably reduce xenophobia and benefit South Africa economically, through brain gain. One of the respondents, Thola stated that:

I think we should not restrict migration from our brother countries. Allowing them to come in will stop xenophobia because this will make us interact more with them and understand them better (Interviewed 12//2/14).

This group favoured unrestricted African migration as they posited that South Africa could benefit economically and socially from sustained and uninhibited contact with other Africans. All nine respondents indicated that they knew Nigerians in the area who had thriving businesses that employed South Africans, as well as Nigerians who were school teachers, medical doctors and lecturers at the University of Zululand, all of who contributed to economic growth and the development of Empangeni. This concurs with the notion of the 
contact theory that the sustained interaction of diverse groups eventually results in the reduction of prejudice and the development of conviviality (Dixon et al 2005). Simply put, they argue that unrestricted immigration policies will produce frequent intergroup contact, which will eventually lead to the demise of othering. "This group generally favour a convergence of cultures, i.e., getting the best of two cultures, they expect open-mindedness that will allow for cosmopolitanism to thrive in their desire for a culturally integrated Africa" (Isike 20I5: I80).

The respondents were also asked how their interactions with various Nigerians have influenced the nature of their relationships. Twenty-six South African respondents stated that before they came into contact with their Nigerian dyads, they had various negative perceptions and stereotypes about Nigerians. For example, one stated that:

I always thought Nigerians were criminals... Not that I really knew them. But after being friends with Nkechi, I got to understand who they are. Their culture is so beautiful, yoh! The clothes and food is (are) so fantastic. I can even cook egusi (a Nigerian dish that is prepared mainly with melon seeds)... These Nigerians are not so different from us as we assume (Interviewed 24/07//4).

In this case, it is evident that contact enabled the development of a convivial relationship and the entanglement of differences. This is the result of the intermingling of cultures between the South Africans and the Nigerian migrants. It supports Dovidio et al's (20I3) assertion that intergroup contact produces self-other merging, where the in-group looks beyond diversities and sees the out-group as similar to it.

However, in a few cases, contact fostered hostility. Paul's contact with his Nigerian friend did not change his prejudice and stereotypes towards Nigerians who he said should be prevented from immigrating to South Africa as they distort the sociocultural fabric of the nation. Based on the contact premise, Paul's friendship with a Nigerian should have removed his prejudice, but the opposite was the case. Paul developed antipathy towards Nigerians irrespective of sustained contact with a Nigerian dyad. This concurs with Durrheim et al's (2014) argument that beyond the reduction of prejudice is the paradoxical effects of intergroup contact which include recategorization, anxiety reduction, and promotion of empathy. Another typical example is that of Thando, who explained that his interaction with a Nigerian migrant did not change his perceptions but made him perceive them as culturally different and increased his prejudice. Here, cultural differences impacted negatively on developing intimacy of contact. In these two cases, prejudice and exclusion did not dissolve with contact and interaction; rather, it perpetuated and heightened them. This paradoxical effect of contact does not imply that the theory is inadequate in the study of intergroup relations, but rather that it does not work as expected in all cases. While its argument that sustained contact produces conviviality and tolerance between diverse groups is to some extent valid, such contact can also produce the opposite effect of hostility and exclusion.

\section{Conclusion}

This article examined South Africans' perceptions of and response to Nigerian migration using the contact theory. The findings show that intergroup contact between South Africans and Nigerian migrants had a paradoxical effect on the nature of their relationships. In most cases, it fostered conviviality and entanglement of relations and to a lesser extent latent xenophobic sentiments and hostility were resuscitated through contact. The author thus agrees with the contact theory's postulation that sustained contact could ultimately produce conviviality among diverse groups but this is not a given as contact does not simply reduce prejudice or always produce social proximity. In the case of the South Africans and Nigerian immigrants presented here, it is argued that conviviality between the two groups evolved due to intimacy of contact. On the other hand, in some cases, contact did not remove stereotypes, but rather fuelled them due to the recognition of economic and cultural diversities. Therefore, it is not possible to draw a parallel line between concord and discord as there are meeting points that are facilitated by factors that foster conviviality and entanglement on the one hand and those such as language, stereotypes and perceived economic and social differences which breed xenophobia and exclusion on the other.

Based on these findings, a way forward is for the South African government to review its immigration policy in relation to Africans. Contact theorists argue that one of the ways to ensure that contact produces conviviality is through institutional norms that favour intergroup contact (Pettigrew and Tropp 2006). Conviviality at the top will complement the convivial culture that exists at the bottom and this will provide a conducive environment for contact to foster positive relations.

\section{Acknowledgment}

This article is drawn largely from my doctoral thesis titled "Ties that Bind: A Network Analysis of Relations between Nigerian Migrants and South Africans in Umhlathuze" submitted to the University of KwaZulu-Natal in December 2015. 


\section{References}

Amin, A. 2002. Ethnicity and the Multicultural City: Living with Diversity. Environment and Planning A 34: 959-80.

Amin, A. 2012. Land of Strangers. Cambridge: Polity Press.

Babbie, E. and Mouton, J. 2006. The Practice of Social Research. South African Edition. Oxford University Press Southern Africa: Cape Town.

Balzacq, T. and Carrera, S. 2006. The Hague Programme: The Long Road to Freedom, Security and Justice in Security versus Freedom? A Challenge for Europe's Future. Aldershot: Ashgate Publishing Limited.

Bennet J.C. 20I I. Assimilation and the Persistence of Culture. The New Criterion. 33(4): 29-34.

Bless, C. and Higson-Smith, C. 1995. Fundamentals of Social Research Methods: An African Perspective. Cape Town: Juta.

Brewer MB, Miller N. 1984. Beyond the contact hypothesis: theoretical perspectives on desegregation. In N. Miller and M.B. Brewer (eds), Groups in Contact: The Psychology of Desegregation. New York: Academy Press.

Carter, J. and Jones, T. 1989. Social Geography: An Introduction to Contemporary Issues. London: Edward Arnold.

Crush, J and Ramachandran, S.R. 2014. Migrant Entrepreneurship Collective Violence and Xenophobia in South Africa. Migration Policy series no. 67. Southern African Migration Programme

(SAMP) http://www.queensu.ca/samp/sampresources/sam ppublications/policyseries/Acrobat67.pdf

Dixon, J. Durrheim, K. Kerr, B. and Thomae, M. 2013. Special Thematic Section on Societal Change: What's So Funny 'Bout Peace, Love and Understanding? Further Reflections on the Limits of Prejudice Reduction as a Model of Social Change. Journal of Social and Political Psychology. I(I). 239-252.

Dixon, J.A. and Durrheim, K. 2003. Contact and the Ecology of Racial Division: Some Varieties of Informal Segregation. British Journal of Social Psychology, 42: I-23.

Dixon, J.A. Tredoux, C. and Clack, B. 2005. On the Micro-ecology of Racial Division: A Neglected Dimension of Segregation. South African Journal of Psychology, 35: 395- 4II.

Dovidio, J. F. Johnson, J. D. Gaertner, S. L., Pearson, A. R., Saguy, T. and Ashburn-Nardo, L. 2010. Empathy and Intergroup Relations. In $M$. Mikulincer, and Shaver, P. R. (eds.), Prosocial Motives, Emotions, and Behavior: The Better Angels of our Nature. 393-408. Washington, DC, US: American Psychological Association.
Durrheim, K. Jacobs, N. and Dixon, J. 2014. Explaining the Paradoxical Effects of Intergroup Contact: Paternalistic Relations and System Justification in Domestic Labour in South Africa. International Journal of Intercultural Relations 4I: I50-164

Enos, R.D. 20I4. Causal Effect of Intergroup Contact On Exclusionary Attitudes. Proc Natl Acad Sci. III(I0): 3699-3704.

Everett, J. A. C. and Onu, D. 2013. Intergroup Contact Theory: Past, Present, and Future. The Inquisitive Mind. 13(2). http://www.inmind.org/article/intergroup-contact-theory-pastpresent-and-future

Gilroy, P. 2004. After Empire: Melancholia Or Convivial Culture? London: Routledge.

Hamberger, J. and Hewstone, M. 1997. Inter-ethnic Contact as a Predictor of Prejudice: Tests of a Model in Four West European Nations. British Journal of Social Psychology. 2: 326-342.

Hogg, M.A. 1993. Group Cohesiveness: A Critical review and some new Directions. European Review of Social Psychology 4: 85-III.

Hugo, G. 2005. Migrants in society: diversity and cohesion. A paper prepared for the Policy Analysis and Research Programme of the Global Commission on International Migration http://iom.ch/jahia/webdav/site/myjahiasite/shared/ shared/mainsite/policy and research/gcim/tp/TP6. pdf

Isike, E.M. 20I5. Ties that Bind: A Network Analysis of Relations between Nigerian Migrants and South Africans in Umhlathuze. A Doctoral Dissertation, University of KwaZulu-Natal.

McBride, M. 2015. What works to reduce prejudice and discrimination? A review of the evidence. Scottish Centre for Crime and Justice Research http://www.gov.scot/Resource/0048/00487370.pd $f$

Nadler, A. 2002. Inter-group helping relations as power relations: Helping relations as affirming or challenging inter-group hierarchy. Journal of Social Issues, 58: 487-503.

Neuendorf, K. A. 2002. The Content Analysis Guidebook. Thousand Oaks, CA: Sage.

Nuttall, S. 2009. Entanglement: Literary and Cultural Reflection on Post-apartheid. Johannesburg: Wits University Press.

Nyamnjoh, F.B. 20I5. Incompleteness: Frontier Africa and the Currency of Conviviality. Journal of Asian and African Studies. I-18.

Padilla, A. M. and Perez, W. 2003. Acculturation, Social Identity, and Social Cognition: A New Perspective. Hispanic Journal of Behavioral Sciences, 25(I): 35-55. 
Pentikainen, M. 2008. Creating an Integrated Society, Managing Diversity and Human Rights in Europe. European Yearbook of Minority Issues, 6: 329368.

Pettigrew, T. F. 1998. Intergroup Contact Theory. Annual Review of Psychology. 49: 65-85.

Pettigrew, T. F. and Tropp, L. R. 2008. How does Intergroup Contact Reduce Prejudice? Metaanalytic Tests of Three Mediators. European Journal of Social Psychology, 38: 922-934.

Regout, S. 201I. The Integration of Immigrant Communities in France, the United Kingdom and the Netherlands: National models in a European context. In Migration Studies Unit Working Papers, London: London School of Economics and Political Science.

Rivera, M.M. and Rivera, R.V. 2007. Practical Guide to Thesis and Dissertation Writing. Quezon City: KATHA Publishing Inc.

Rothenberg, R. B. 1995. Commentary: Sampling in Social Networks. Connections, I8(I): I04-I I 0.

Rubin, M. and Hewstone, M. 1998. Social Identity Theory's Self-Esteem Hypothesis: A Review and some Suggestions for Clarification. Personality and Social Psychology Review, 2(I): 40-62

Rzepnikowska, A. 2013. Convivial Cultures in Multicultural Manchester and Barcelona: Narratives of Polish Migrant Women. Paper from Euroemigranci Conference, Kraków. http://www.euroemigranci.pl/dokumenty/pokonfe rencyjna/Rzepnikowska.pdf
Schierup, C.U. Hansen, P. and Castles, S. 2006. Migration, Citizenship, and the European Welfare State. Oxford: Oxford University Press.

Stets, J. E. and Burke, P. J. 2000. Identity Theory and Social Identity Theory. Social Psychology Quarterly, (63): 224-237.

Stinson, A. 2009. National Identity and NationBuilding in Post-Apartheid South Africa. Masters Dissertation, Rhodes University.

Tajfel, H. and Turner, J. C. 1979. An integrative theory of intergroup conflict In W. G. Austin and S. Worchel (eds.), The Social Psychology of Intergroup Relations. Monterey, CA: Brooks/Cole. Cited in M. Rubin and M. Hewstone 1998. Social Identity Theory's Self-Esteem Hypothesis: A Review and some Suggestions for Clarification. Personality and Social Psychology Review 2(I): 4062.

Turner, R. N. Crisp, R. J. and Lambert, E. 2007. Imagining Intergroup Contact Can Improve Intergroup Attitudes. Group Processes \& Intergroup Relations, I0(4): 427-44I.

Vermeulen, V. 1997. Introduction. In H. Vermeulen. (ed.). Immigrant Policy for a Multicultural Society: A Comparative Study of Integration, Language and Religious Policy in Five Western European Countries. Brussels: Migration Policy Group. 5-14. Yeoh, B.S.A. 2013. Upwards or Sideways Cosmopolitanism? Talent/Labour/Marriage Migrations in the Globalising City-state of Singapore. Migration Studies, I ( I): 96-I I6 